\title{
ATIVIDADE ANTIOXIDANTE DE BIOPOLÍMEROS DE INTERESSE INDUSTRIAL OBTIDOS A PARTIR DE FUNGOS ISOLADOS DO SEMI-ÁRIDO NORDESTINO
}

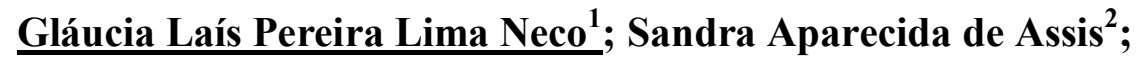 \\ 1. Bolsista PIBIC/CNPq, Graduando em Farmácia, Universidade Estadual de Feira de Santana, e-mail: \\ glaucialaisneco@hotmail.com \\ 2. Orientador, Departamento de Saúde, Universidade Estadual de Feira de Santana, e-mail: sandrinhaassis@yahoo.com.br
}

PALAVRAS-CHAVE: Micro-organismos; semi-árido; antioxidante.

\section{INTRODUÇÃO}

Os biopolímeros são os mais abundantes compostos orgânicos da biosfera, são produzidos por organismos vivos, sendo representado principalmente pelos polissacarídeos e as proteínas (FUKUDA, 2007).

Para um eficiente processo de produção de polissacarídeos deve-se considerar desde o microrganismo em estudo até a determinação dos parâmetros ambientais e bioquímicos ideais (FARIA, 2002). Desse modo, a região do semiárido baiano representa um grande campo à bioprospecção, pois microrganismos nativos desse ambiente podem ser dotados de características próprias, com peculiaridades de interesse industrial.

Os radicais livres são átomos ou moléculas reativas, normalmente produzidas pelos organismos vivos, sendo resultado de diversos processos metabólicos que envolvem a transferência de elétrons. Apresentam elétrons não pareados em sua órbita externa o que lhes garante característica reativa, justificada pela tendência de receber ou doar elétrons na tentativa de se estabilizarem (CONTRERAS et al., 2004).

Os antioxidantes podem ser definidos como sendo uma substância que presente em baixas concentrações em relação ao substrato oxidável, regenera ou previne de maneira eficaz a oxidação desse substrato (HALLIWELL, 2000). O pontencial de um antioxidante se dá pelas suas características químicas, como a presença de doadores de elétrons ou de hidrogênio; capacidade de deslocamento do radical formado em sua estrutura; potencial de quelar metais de transição envolvidos no processo oxidativo e facilidade de acesso ao local de ação (MANACH e DONOVAN, 2004).

\section{METODOLOGIA}

Os microrganismos foram obtidos da coleção de cultura de microrganimos da Bahia (CCMB, Feira de Santana, Brasil). As leveduras são pertencentes às espécies Cryptococcus liquefaciens, (302), Aureobasidium pululans (324) e Rhodotorula orizycola (D2T6-1).

\section{Avaliacão da Capacidade antioxidante total}

Ensaio baseado na redução do molibdênio ${ }^{+6}$ para molibdênio $^{+5}$ por composto antioxidante levando a formação do complexo fosfomolibdênio. Realizado a partir de uma alíquota de $0,1 \mathrm{~mL}$ de cada solução amostra, contendo EPS em diferentes concentrações $(2,4$, 6,8 , e $\left.10 \mathrm{mg} \cdot \mathrm{mL}^{-1}\right)$ foi misturada em um microtubo com $1 \mathrm{~mL}$ da solução reagente $(0,6 \mathrm{M}$ de ácido sulfúrico, $28 \mathrm{mM}$ de fosfato de sódio, $4 \mathrm{mM}$ de molibdato de amônio). Os tubos foram incubados a $95^{\circ} \mathrm{C}$ por 90 minutos. Após o resfriamento das amostras à temperatura ambiente, a absorbância mensurada em $695 \mathrm{~nm}$. Os resultados expressos a partir da equação da reta obtida da curva de calibração do ácido ascórbico.

\section{Método de Sequestro de radicais livres $(\cdot \mathrm{DPPH})$}

A atividade antioxidante determinada pela capacidade do $\beta$-glicano em reagir com o radical livre DPPH. Inicialmente foi preparado o radical DPPH e as amostras $(1 \mathrm{mg} / \mathrm{mL})$. Em seguida, as misturas reacionais foram feitas a partir da adição de $1700 \mu \mathrm{L}$ da solução etanólica de DPPH $(50 \mu \mathrm{M})$, das amostras do $\beta$-glicano em diferentes concentrações $(1,25$ a 150 
$\mu \mathrm{g} / \mathrm{mL}$ ) e de etanol a fim de completar o volume da reação para $2 \mathrm{~mL}$. Estas misturas foram incubadas por 20 min a $20^{\circ} \mathrm{C}$ e a absorbância residual do $\cdot \mathrm{DPPH}$ medida a $517 \mathrm{~nm}$. O zero do aparelho é obtido com etanol.

\section{Método de Reducão do Radical ABTS•+}

A capacidade dos polissacarídeos em promover redução do radical ABTS + foi realizado inicialmente a partir do preparo deste por meio da mistura de uma solução de ABTS e persulfato de potássio, sendo as amostras preparadas a uma concentração de $1 \mathrm{mg} / \mathrm{mL}$. As amostras em diferentes concentrações $(1,25$ a $150 \mu \mathrm{g} / \mathrm{mL})$ foram adicionadas a $1700 \mu \mathrm{L}$ da solução etanólica de ABTS $+(7 \mu \mathrm{M})$, sendo o etanol empregado para completar o volume da reação para $2 \mathrm{~mL}$. As misturas reacionais foram incubadas por 6 min a $25^{\circ} \mathrm{C}$ no escuro. Após incubação, a absorbância das misturas reacionais foram obtida por espectrofotometria a 734 nm. O zero do aparelho é obtido com etanol e ácido gálico é usado como padrão.

\section{RESULTADOS E/OU DISCUSSÃO}

Para a análise da capacidade antioxidante total, todas as amostras analisadas demonstraram possuir atividade antioxidante expressa em equivalente a ácido ascórbico. A atividade antioxidante das amostras foram estudadas nas concentrações de 2, 4, 6, 8 e $10 \mathrm{mg} / \mathrm{mL}$.

Comparado ao ácido ascórbico todas as amostras estudadas apresentaram potencial antioxidante, sendo para o exopolissacarídeo o micro-organismo CCMB D2T6-1 apresentou a maior inibição na concentração de $10 \mathrm{mg} / \mathrm{mL}$ (equivalente a $165 \mu \mathrm{g} / \mathrm{mL}$ a Ácido Ascórbico). O polissacarídeo do micro-organismo CCMB 302 apresentou o valor mais significativo na concentração de $10 \mathrm{mg} / \mathrm{mL}$ (equivalente a $194 \mu \mathrm{g} / \mathrm{mL}$ a Ácido Ascórbico), seguido do polissacarídeo CCMB D2T6-1 (equivalente a $120 \mu \mathrm{g} / \mathrm{mL}$ a Ácido Ascórbico). Pode-se observar que o perfil de inibição é concentração-dependente, ou seja, quanto mais concentrada a mostra, maior será o a porcentagem de inibição.
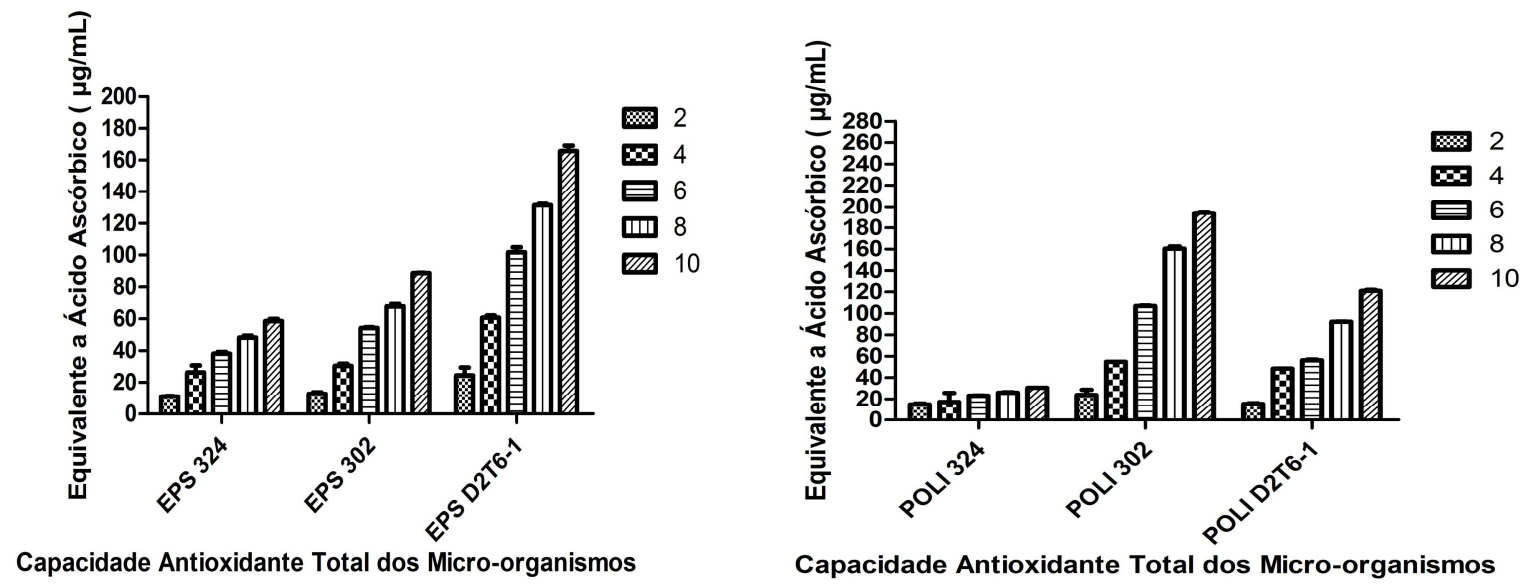

Figura 01: Estudo da atividade antioxidante em diferentes concentrações do Poli e EPS, pelo método da capacidade antioxidante total pelo método fosfomolibdenio.

Método de Sequestro de radicais livres $(\cdot \mathrm{DPPH})$

Por esse método de sequestro de radical, o exopolissacarideo CCMB D2T6-1 foi que teve um melhor resultado inibindo 43,59\%, seguido do exopolissacarídeo CCMB 324 com $42,48 \%$ de inibição. Avaliando o percentual de inibição do radical DPPH pele polissacarídeo das leveduras do estudo, o polissacarídeo CCMB 302 e CCMB 324 apresentou um percentual de inibição semelhante em maiores concentrações, chegando a inibir 60,09\% e 60,04\% nas 
concentrações de $10 \mathrm{mg} / \mathrm{mL}$. Já o polissacarideo CCMB D2T6-1, na maior concentração estudada (10 mg/mL) inibiu 47,69\% do radical DPPH como mostra a figura 02 .
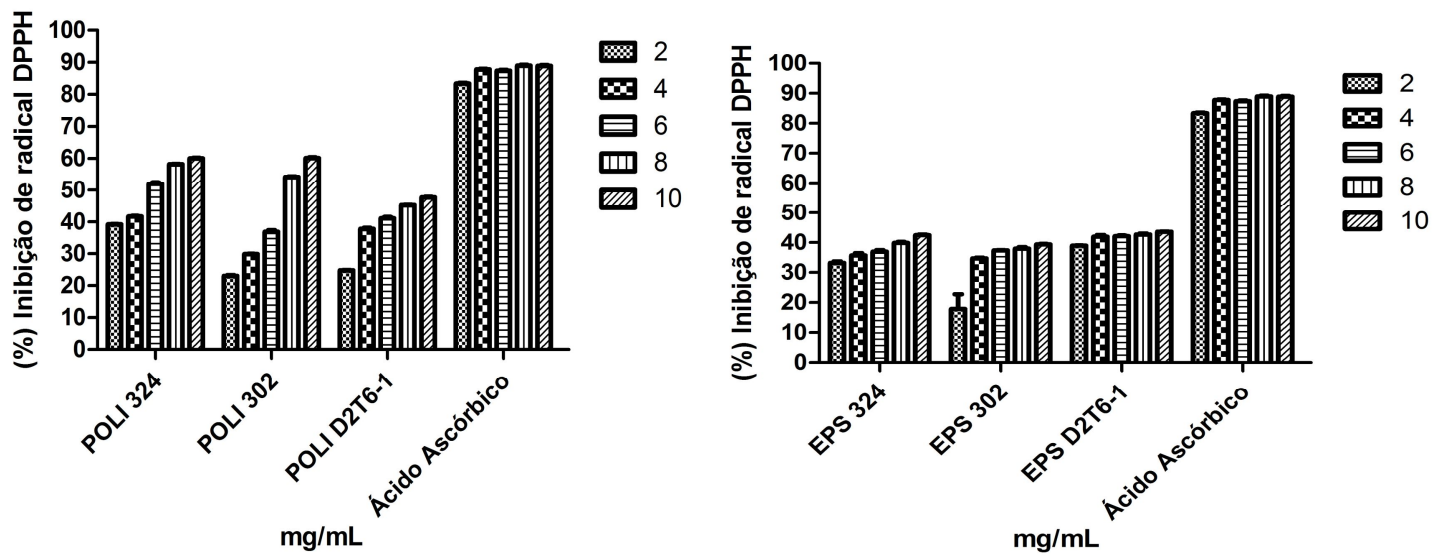

Figura 02: Relação entre as diferentes concentrações dos Poli e EPS e ácido ascórbico para avaliação do percentual de inibição do radical DPPH.

\section{$\underline{\text { Remoção de radical ABTS }}$}

A avaliação de atividade antioxidande do exopolissacarideo das leveduras estudadas não mostraram percentuais significativos para a inibição do radical ABTS. A inibição máxima foi pouco superior a 10\% (10,26\%) pelo exopolissacarídeo CCMB D2T6-1, considerada estatisticamente insatisfatória. A fração do polissacarídeo foi um pouco superior que nos exopolissacarídeo estudados, porém estatisticamente em valores insatisfatório para ser utilizado como inibidor por esse mecanismo nessas concentrações. $\mathrm{O}$ maior percentual de inibição encontrado foi $19,20 \%$ pelo polissacarídeo CCMB 324 em concentração de $10 \mathrm{mg} / \mathrm{mL}$.
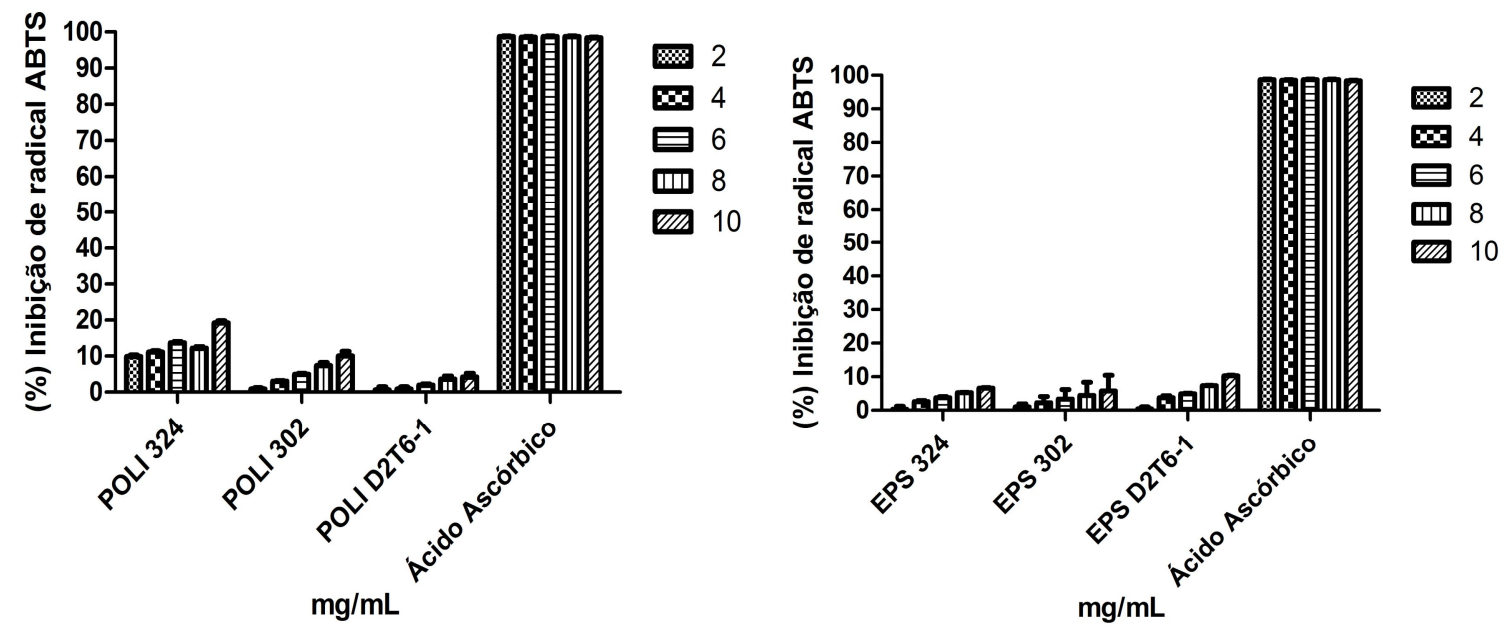

Figura 03: Relação entre as diferentes concentrações Poli e EPS e ácido ascórbico para avaliação do percentual de inibição do radical ABTS. 


\section{CONSIDERAÇÕES FINAIS}

Os antioxidantes podem agir nos organismos vivos por diferentes mecanismos e existem vários métodos pra determinar essa atividade, os micro-organismos estudados apresentaram efeito notavel na eliminação de radicais livres pelo método de análise da capacidade antioxidante total e pelo sequestro do radical DPPH, revelando-se um promissor agente na terapia antioxidante. Assim, estudos que venham agregar mais informações sobre a capacidade antioxidante destes micro-organismos, contribuem grandemente para a prospecção de novos produtos de origem biotecnológica.

\section{REFERÊNCIAS}

CONTRERAS, G. O. et al. Antioxidantes y aterosclerosis. Revista de Endocrinología y Nutrición. v. 12, n. 4, p. 199-206, 2004.

FARIA L.H.B. Caracterização taxonômica e produção de polissacarídeos utilizando bactérias Isoladas de amostras do solo. [Dissertação] Universidade Estadual Paulista. São José do Rio Preto, 2002.

FUKUDA,E.K. Extração, purificação e caracterização de Polissacarídeos da biomassa do fungo Ascomiceto botryosphaeria rhodina mamb-05. [Dissertação] Faculdade Estadual de Londrina, 2007.

HALLIWELL B., GUTTERIDGE J.M.C. Role of free radicals and catalytic metal ions in human disease: an overview. Methods in Enzymology, v. 186, p. 1-85, 2000.

MANACH, C., DONOVAN, J. Pharmacokinetics and metabolism of dietary flavonoids in humans. Free radical Research. v. 38, n.8, p.771-785, 2004. 